\title{
Hunger and associated harms among injection drug users in an urban Canadian setting
}

\author{
Aranka Anema ${ }^{1,2}$, Evan Wood ${ }^{1,2}$, Sheri D Weiser ${ }^{3,4}$, Jiezhi Qi ${ }^{1}$, Julio SG Montaner ${ }^{1,2}$, Thomas Kerr ${ }^{1,2^{*}}$
}

\begin{abstract}
Background: Food insufficiency is often associated with health risks and adverse outcomes among marginalized populations. However, little is known about correlates of food insufficiency among injection drug users (IDU).

Methods: We conducted a cross-sectional study to examine the prevalence and correlates of self-reported hunger in a large cohort of IDU in Vancouver, Canada. Food insufficiency was defined as reporting "I am hungry, but don't eat because I can't afford enough food". Logistic regression was used to determine independent sociodemographic and drug-use characteristics associated with food insufficiency.

Results: Among 1,053 participants, 681 (64.7\%) reported being hungry and unable to afford enough food. Selfreported hunger was independently associated with: unstable housing (adjusted odds ratio [AOR]: 1.68, 95\% confidence interval [Cl]: $1.20-2.36$, spending $\geq \$ 50 /$ day on drugs (AOR: $1.43,95 \% \mathrm{Cl}: 1.06-1.91$ ), and symptoms of depression (AOR: 3.32, 95\% Cl: 2.45 - 4.48).

Conclusion: These findings suggest that IDU in this setting would likely benefit from interventions that work to improve access to food and social support services, including addiction treatment programs which may reduce the adverse effect of ongoing drug use on hunger.
\end{abstract}

\section{Background}

There were between 155 and 250 million illicit drug users worldwide in 2009 [1], including an estimated 16 million injection drug users (IDU) [2]. IDU face multiple structural and behavioral barriers to accessing health care and social support services, which collectively serve to compound health risks and exacerbate poor health outcomes [3]. IDU are known to be vulnerable to developing nutritional deficiencies, and often simultaneously experience numerous forms of micro and macronutrient deficiencies $[4,5]$.

Insufficient consumption of food among IDU has been associated with an array of harms. Caloric insufficiency has been correlated with decreased immune function [6] and elevated risk of receiving a positive tuberculin test [7]. Insufficient caloric intake has been additionally associated with increased risk of various health complications including invasive candidiasis, viral hepatitis, bacterial pneumonia, and various infections including

\footnotetext{
* Correspondence: uhritk@cfenet.ubc.ca

'British Columbia Centre for Excellence in HIV/AIDS, St. Paul's Hospital,

Vancouver, BC, Canada

Full list of author information is available at the end of the article
}

subcutaneous and perianal abscesses among IDU [5]. Studies evaluating the prevalence of nutritional deficiencies among IDU have tended to focus on HIV-infected populations [8,9]. In high resource settings, self-reported hunger, a marker of food insufficiency, has been found to be particularly elevated among IDU living with HIV/ AIDS [10]. Self-reported hunger has been additionally correlated with unprotected sex and risk of HIV transmission, which is believed to be a result of survival sex-trade involvement [11].

Little is known about the social and behavioral risk factors, independent of HIV infection, that contribute to food insufficiency among IDU. We therefore sought to evaluate the prevalence of and socio-demographic and drug-using characteristics associated with self-reported hunger in a cohort of HIV-negative IDU in British Columbia, Canada.

\section{Methods}

The Vancouver Injection Drug Users Study (VIDUS) was initiated in May 1996. VIDUS has been described in detail previously [12]. Briefly, participants were eligible for inclusion in VIDUS if they had injected illicit drugs 
at least once in the past month, lived in the Greater Vancouver region and if they provided written informed consent. At baseline, and semiannually thereafter, VIDUS participants provide blood samples for laboratory analysis, and completed an interviewer-administered questionnaire. The VIDUS questionnaire elicits information about socio-demographic status, injection and non-injection drug use, HIV risk behavior, income generation, encounters with police, and health service utilization. The questionnaire is based on a previous instrument developed for adult drug users, and has been found to reliably identify factors associated with HIV infection and other harms [13]. Participants receive an honorarium of $\$ 20 \mathrm{CDN}$ for each study visit. Ethical approval for VIDUS is obtained on an annual basis from the Providence Health Care/University of British Columbia Research Ethics Board.

Questions regarding hunger were first included in the VIDUS instrument in December 2005. All individuals who completed a baseline interview between December, 2005 and March, 2009 were included in this analysis. Hunger is considered to be a severe manifestation of food insecurity [14]. Self-reported hunger, the primary dependent variable, was defined as answering 'yes' to the question: "I am hungry, but don't eat because I can't afford enough food". This definition of current selfreported was extracted from a validated food insecurity scale published by Radimer/Cornell [14]. Independent from the validated scale, this individual statement has been tested, and shown to have good specificity and sensitivity when compared to dietary proxies of food insufficiency in five North American settings [15].

In this cross-sectional analysis, we examined the point prevalence of self-reported hunger among IDU in relation to the following socio-demographic variables: median age, gender (male vs. female), ethnicity (Aboriginal vs. other), incarceration in the last 6 months (yes vs. no). We also explored several markers of socioeconomic status including: a) downtown eastside residency (yes vs. no), which is a community known as Canada's poorest postal code, and is characterized by high prevalence of unstable housing and illicit drug use $[16,17]$, b) unstable housing (single-room occupancy dwelling, shelter, hostel, treatment centre or no fixed address vs. apartment or house), and c) current education status (high school or greater vs. other). We also examined self-reported symptoms of depression in the past week ( $\geq 16$ CES-D score vs. < 16 CES-D score). Illicit drug use behaviors considered included: a) daily heroin injection in the past six months (yes vs. no), b) daily non-injection crack/ rock in the past six months (yes vs. no), c) daily injection cocaine in the past six months (yes vs. no), d) any injection or non-injection crystal methamphetamine in the past six months (yes vs. no), e) any injection or non-injection drug binge in the past six months, defined as '[a time when you] injected drugs more than usual, or used any non-injection drugs more than usual' (yes vs. no), f) daily alcohol use ( $\geq 4$ drinks vs. $<4$ drinks), and g) difficulty accessing drug/alcohol treatment (yes vs. no), and h) money spent on drugs per day ( $\geq$ CAD $\$ 50$ vs. < CAD $\$ 50)$. All behavioral variable definitions were identical to previous reports [18].

Univariate statistics were used to determine factors associated with self-reported hunger. Categorical explanatory variables were analyzed using Pearson's ChiSquare test, and continuous variables were analyzed using the Wald test. Degrees of freedom (df) were equal to one $(\mathrm{df}=1)$ for all variables, with the exception of the 'symptoms of depression' variable, which was equal to $2(\mathrm{df}=2)$ in both unadjusted and adjusted analyses. A multivariate model was then prepared using an a priori defined approach whereby variables that were associated with food insufficiency $(p<0.05)$ in univariate analyses were included in a fixed logistic regression model. Wald Chi-Squared tests were applied to all categorical and continuous variables. The concordance index was used to determine the final model fit [19], and the tolerance and variance inflation factor and condition index were used to assess multi-collinearity of the final model. All statistical analyses were performed using SAS software version 9.1 (SAS, Cary, NC). All reported $\mathrm{p}$-values were two-sided.

\section{Results}

A total of 1,053 participants were eligible for the present analyses. Overall, the median age was 41.6 years [interquartile range (IQR) 34.9 - 47.5]; 353 (33.5\%) were female; and 307 (29.2\%) self-identified as being of Aboriginal ancestry. Overall, 544 (51.7\%) of participants had accessed a food bank or meal program in the past six months. A total of 681 (64.7\%) IDU reported being hungry but not eating due to an inability to afford food.

Socio-demographic and drug-use characteristics associated with self-reported hunger in univariate analyses are shown in Table 1. Unadjusted factors associated with self-reported hunger among IDU included: being younger in age (Odds Ratio [OR] $=0.98$, 95\% Confidence Interval [CI]: 0.97-0.99, $p=0.005)$; downtown eastside residency (OR 2.07, 95\% CI: 1.59-2.70, $p<$ 0.001 ); living in unstable housing (OR 2.27, 95\% CI: 1.74-2.96, $p<0.0001)$; spending $\geq$ CAD $\$ 50 /$ day on drugs (OR: 2.00, 95\% CI: 1.55-2.58, $p<0.001$ ); and being incarcerated in the last six months $(1.50,95 \% \mathrm{CI}$ : $1.06-2.11, p=0.021)$. Symptoms of depression in the past week were also associated with self-reported hunger (OR 3.73, 95\% CI: 2.80-4.98, $p<0.001$ ). Drug use characteristics associated with self-reported hunger included: daily injection heroin in the last six months (OR 1.76, 
Table 1 Factors associated with food insufficiency among injection drug users $(n=1,053)$

\begin{tabular}{|c|c|c|c|c|c|}
\hline Characteristics & $\begin{array}{c}\text { Yes } \\
65(\%) \\
\mathrm{N}=681\end{array}$ & $\begin{array}{c}\text { No } \\
35 \text { (\%) } \\
N=372\end{array}$ & $\begin{array}{l}\text { Odds Ratio } \\
(95 \% \mathrm{Cl})\end{array}$ & Chi-Square $^{t, \neq}$ & $p$-value \\
\hline \multicolumn{6}{|l|}{ Socio-demographic } \\
\hline \multicolumn{6}{|l|}{ Age } \\
\hline Median (IQR) & $41.1(34.5-46.7)$ & $42.8(35.9-49.4)$ & $0.98(0.97,0.99)$ & 7.75 & 0.005 \\
\hline \multicolumn{6}{|l|}{ Gender } \\
\hline Male & $455(66.81 \%)$ & $245(65.86 \%)$ & $1.04(0.80,1.36)$ & 0.10 & 0.754 \\
\hline Female & $226(33.19 \%)$ & $127(34.12 \%)$ & & & \\
\hline \multicolumn{6}{|l|}{ Aboriginal identity } \\
\hline Yes & $189(27.75 \%)$ & $118(31.72 \%)$ & $0.83(0.63,1.09)$ & 1.83 & 0.176 \\
\hline No & $492(72.25 \%)$ & $254(68.28 \%)$ & & & \\
\hline \multicolumn{6}{|l|}{ DTES Residency } \\
\hline Yes & $496(72.83 \%)$ & $210(56.45 \%)$ & $2.07(1.59,2.70)$ & 29.22 & $<0.001$ \\
\hline No & $185(27.17 \%)$ & $162(43.55 \%)$ & & & \\
\hline \multicolumn{6}{|l|}{ Unstable housing } \\
\hline Yes & $504(74.01 \%)$ & 207 (55.65\%) & $2.27(1.74,2.96)$ & 36.99 & $<0.0001$ \\
\hline No & 177 (25.99\%) & $165(44.35 \%)$ & & & \\
\hline \multicolumn{6}{|l|}{ Education status } \\
\hline High school or greater & $345(50.66 \%)$ & $205(55.11)$ & $0.84(0.65,1.08)$ & 1.91 & 0.167 \\
\hline Other & $336(49.34 \%)$ & $167(44.89 \%)$ & & & \\
\hline \multicolumn{6}{|c|}{ Money spent on drugs per day } \\
\hline$\geq \$ 50$ & $422(61.97 \%)$ & $167(44.89 \%)$ & $2.00(1.55,2.58)$ & 28.46 & $<0.001$ \\
\hline$<\$ 50$ & $259(38.03 \%)$ & $205(55.11 \%)$ & & & \\
\hline \multicolumn{6}{|l|}{ Incarceration ** } \\
\hline Yes & $138(20.26 \%)$ & $54(14.52 \%)$ & $1.50(1.06,2.11)$ & 5.33 & 0.021 \\
\hline No & $543(79.74 \%)$ & $318(85.48 \%)$ & & & \\
\hline \multicolumn{6}{|l|}{ Clinical } \\
\hline \multicolumn{6}{|l|}{ Symptoms of depression * } \\
\hline$\geq 16$ CES-D & $456(66.96 \%)$ & 159 (42.74\%) & $3.73(2.80,4.98)$ & 88.19 & $<0.001$ \\
\hline$<16$ CES-D & $136(19.97 \%)$ & $177(47.48 \%)$ & & & \\
\hline \multicolumn{6}{|l|}{ Drug Use } \\
\hline \multicolumn{6}{|l|}{ Daily injection heroin** } \\
\hline Yes & $240(35.24 \%)$ & $88(23.66 \%)$ & $1.76(1.32,2.34)$ & 15.06 & $<0.001$ \\
\hline No & $441(64.76 \%)$ & $284(76.34 \%)$ & & & \\
\hline \multicolumn{6}{|c|}{ Daily non-injection crack/rock ** } \\
\hline Yes & $321(47.14 \%)$ & $111(29.84 \%)$ & $2.10(1.60,2.74)$ & 29.75 & $<0.001$ \\
\hline No & $360(52.86 \%)$ & $261(70.16 \%)$ & & & \\
\hline \multicolumn{6}{|l|}{ Daily injection cocaine ${ }^{* *}$} \\
\hline Yes & 69 (10.13\%) & $28(7.53 \%)$ & $1.39(0.88,2.19)$ & 1.95 & 0.162 \\
\hline No & $612(89.87 \%)$ & $344(92.47 \%)$ & & & \\
\hline \multicolumn{6}{|c|}{ Any injection or non-injection crystal meth ${ }^{* *}$} \\
\hline Yes & $28(4.11 \%)$ & $9(2.42 \%)$ & $1.73(0.81,3.71)$ & 2.03 & 0.154 \\
\hline No & $653(95.89 \%)$ & $363(97.58 \%)$ & & & \\
\hline \multicolumn{6}{|c|}{ Any injection or non-injection drug binge $\mathrm{e}^{* *}$} \\
\hline Yes & $352(51.69 \%)$ & $146(39.25 \%)$ & $1.66(1.28,2.14)$ & 14.94 & 0.001 \\
\hline No & $329(48.31 \%)$ & $226(60.75 \%)$ & & & \\
\hline \multicolumn{6}{|l|}{ Daily alcohol use } \\
\hline$<=4$ drinks & $496(72.83 \%)$ & $279(75.00 \%)$ & $1.12(0.84,1.49)$ & 0.58 & 0.446 \\
\hline$>4$ & $185(27.17 \%)$ & $93(25.00 \%)$ & & & \\
\hline
\end{tabular}


Table 1 Factors associated with food insufficiency among injection drug users $(\mathbf{n}=\mathbf{1 , 0 5 3 )}$ (Continued)

\begin{tabular}{lcccc}
\hline Difficulty accessing drug/alcohol treatment & & & & \\
Yes & $38(5.58 \%)$ & $14(3.76 \%)$ & $1.51(0.81,2.83)$ & 1.69 \\
No & $643(94.42 \%)$ & $358(96.24 \%)$ & & 0.193 \\
\hline
\end{tabular}

* Data missing for 125 participants

** In the past six months

${ }^{+}$All Chi-Square tests were performed with one degree of freedom $(\mathrm{df}=1)$, with the exception of the 'symptoms of depression' variable, where $\mathrm{df}=2$.

₹ Chi-Squared Test were applied to all categorical variables. A Wald Test was applied to the continuous 'age' variable, yielding a Wald Chi-Square value.

95\% CI: 1.32-2.34, $p<0.001)$; daily non-injection crack/ rock in the last six months (OR 2.10, 95\% CI: 1.60-2.74, $p<0.001)$; and any injection or non-injection drug binge in the past six months (OR 1.66, 95\% CI: 1.28 2.14, $p<0.001)$.

Results from the multivariate analysis are shown in Table 2. Variables independently associated with selfreported hunger in multivariate analysis included: unstable housing (adjusted odds ratio [AOR]: 1.68, 95\% confidence interval $[\mathrm{CI}]: 1.20-2.36, \mathrm{p}=0.003)$, spending $>\$ 50 /$ day on drugs (AOR: 1.43, CI: $1.06-1.91, \mathrm{p}=$ 0.018 ), and symptoms of depression (AOR: 3.32, 95\% CI: $2.45-4.48, \mathrm{p}=<0.001)$. The statistical significance of these variables was found to be unchanged when reestimating the multivariate model with removal of nonsignificant variables.
The p-value for Hosmer and Lemeshow Goodness-ofFit Test was greater than 0.05 , which indicates the model fit the data at an acceptable level. The concordance index was greater than 0.5 , which implies a good probability of concordance between predicted and observed responses. The tolerance and variance inflation factor were examined for each variable, all of which were greater than 0.2 and less than 5.0, respectively, indicating no concerns with multicollinearity in the final model.

\section{Discussion}

We found a very high prevalence of self-reported hunger among IDU in this Canadian setting, with $65 \%$ of participants meeting criteria for hunger. This is $62 \%$ higher than the prevalence severe food insecurity reported by

Table 2 Logistic Regression analysis of factors associated with food insufficiency among injection drug users ( $\mathrm{n}=1,053)$

\begin{tabular}{|c|c|c|c|c|}
\hline Variable & Adjusted Odds Ratio (AOR) & $\begin{array}{l}\text { 95\% Confidence Interval } \\
(95 \% \mathrm{Cl})\end{array}$ & Wald Chi-Square $^{\dagger, \neq}$ & $p$ - value \\
\hline $\begin{array}{l}\text { Age } \\
\text { (per year increase) }\end{array}$ & 0.994 & $(0.98-1.01)$ & 0.65 & 0.420 \\
\hline $\begin{array}{l}\text { DTES residency } \\
\text { (yes vs no) }\end{array}$ & 1.34 & $(0.96-1.89)$ & 2.89 & 0.089 \\
\hline $\begin{array}{l}\text { Unstable housing } \\
\text { (yes vs no) }\end{array}$ & 1.68 & $(1.20-2.36)$ & 9.04 & 0.003 \\
\hline $\begin{array}{l}\text { Money spent on drugs per day } \\
(\geq \$ 50 \text { vs }<\$ 50)\end{array}$ & 1.43 & $(1.06-1.91)$ & 5.64 & 0.018 \\
\hline $\begin{array}{l}\text { Incarceration ** } \\
\text { (yes vs no) }\end{array}$ & 1.16 & $(0.79-1.69)$ & 0.57 & 0.451 \\
\hline $\begin{array}{l}\text { Symptoms of Depression* } \\
\text { ( } \geq 16 \text { CES-D vs < } 16 \text { CES-D) }\end{array}$ & 3.32 & $(2.45-4.48)$ & 62.79 & $<0.001$ \\
\hline $\begin{array}{l}\text { Daily injection heroin ** } \\
\text { (yes vs no) }\end{array}$ & 1.27 & $(0.92-1.75)$ & 2.05 & 0.152 \\
\hline $\begin{array}{l}\text { Daily non-injection crack/rock ** } \\
\text { (yes vs no) }\end{array}$ & 1.18 & $(0.86-1.61)$ & 1.02 & 0.313 \\
\hline $\begin{array}{l}\text { Any injection or non-injection drug binge ** } \\
\text { (yes vs no) }\end{array}$ & 1.15 & $(0.86-1.53)$ & 0.90 & 0.342 \\
\hline
\end{tabular}


the general Canadian population [20]. Self-reported hunger in this population was associated with low socioeconomic status, symptoms of depression, and competing demands for food and drugs.

We found that self-reported hunger was not associated with use of specific types of illicit drugs. Rather it appeared to be predicted by the amount of drug use, as approximated by expenditures on drugs. Sixty two percent of hungry IDU spent over CAD $\$ 50 /$ day, or > CAD $\$ 18,000 /$ year. Similar habitual drug expenditures have been reported by cocaine and heroin users in the United States (U.S.) [21]. Our findings build upon previous studies that have found that IDU using multiple drugs, and over a long period of time, have significantly higher odds of being nutritionally deficient [4]. Drug addiction has shown to modify eating habits, often causing individual to eat fewer meals during a usual week [22], to skip meals for an entire day [23] and to prioritize drugs over everything else, including food intake [24]. Qualitative interviews with inner-city drug-using women reveal that the decision to buy drugs instead of food, even when hungry, is rationalized by the fact that food can be obtained for free from distribution sites, but getting a 'fix' always costs money [25]. Our findings suggest that IDU in this setting may benefit from improved access to drug treatment services to prevent deterioration of nutritional status.

We also found that $74 \%$ of IDU reporting hunger in our cohort were unstably housed. This proportion is elevated when compared to findings from a 2006 study within the same cohort, which found that $60 \%$ of IDU reported living in a single room occupancy hotel, shelter, recovery or transition house, jail, on the street or at no fixed address [16]. The association between hunger and unstable housing suggests that some IDU may not be accessing adequate nutritional services or housing needed to support food security. Over the past 20 years, a conflation of factors have contributed to high levels of homelessness in the Vancouver downtown eastside, where the majority of participants reside, including government deinstitutionalization of people suffering mental illness and addiction, rapid gentrification of the neighborhood, and insufficient low-cost housing options [17]. As part of the gentrification process, illicit drug users have also been the subject of ongoing police crackdowns on drug use that have forced them into peripheral urban areas [26]. In addition to our data showing that IDU are not accessing housing services [16], recent studies have found that IDU in Vancouver have limited access to essential harm reduction services [26] and delayed access to HIV clinical services [27]. Taken together, these data suggest the need to scale up multiple interventions to improve the health and wellbeing of
IDU, and thereby reduce the problems of food insecurity and hunger among this population.

We found that $67 \%$ of IDU reporting hunger experienced symptoms of depression in the past week and that depression was strongly correlated with hunger. Cross-sectional research suggests that there is a strong association between household food insufficiency and adverse mental health. Food insufficiency has been associated with elevated incidence of major depressive disorders among women and adolescents in the general U.S. population $[28,29]$. Food insecurity has been associated with poor mental health status in HIV-positive populations, which include high proportions of illicit drug users [30-32]. No studies to our knowledge have assessed the correlation between self-reported hunger and symptoms of depression among IDU. Our findings suggest that this population would benefit from receiving mental health screening and support services as part of a comprehensive approach to improving their food security status and mental health.

There are several strengths and limitations to our study. Self-reported hunger is considered to be a severe manifestation of food insecurity [14]. Our measure of hunger has been validated in five North American settings, and has been associated with insufficient food intake [15]. The elevated prevalence of self-reported hunger among IDU in this study therefore likely indicates actual food inadequacy and severe food insecurity.

Because this is a cross-sectional study, we were unable to determine causality, or the biological and social pathways linking self-reported hunger and explanatory variables in this cohort. Longitudinal studies would be valuable to inform understanding of the mediating effect of socio-demographic and drug-use variables on food insufficiency. Longitudinal studies would additionally strengthen the power of similar analyses by enabling the inclusion of time-variant individual differences, and by helping to unpack the direction of causality between food insecurity and relevant demographic and clinical variables.

Common to all studies, it is possible that our study was affected by response bias. Studies evaluating nutritional status have found that self-reported nutritional measures are less reliable than clinical nutrition measures. Research has found that individuals tend to under-report energy intake, weight and BMI, and overreport height [33]. Self-reports of nutritional information often vary by gender and beliefs of social desirability [33].

Future evaluations of food insufficiency among IDU should seek to identify the unique social and biological factors mediating hunger. This is important in light of studies showing that a high proportion of drug users 
report disturbances in their social and familial networks, are underweight, and exhibit anorexia with poor food and drink consumption [5]. Further studies should consider exploring the impact of social support systems on subjective and objective measures of food insufficiency. A comprehensive nutritional evaluation, including dietary recall and body mass index (BMI) would also be valuable given the association between fasting appetite sensations with weight loss [34].

\section{Conclusion}

We found a high prevalence of self-reported hunger among IDU in this marginalized urban setting. Hunger in this population is associated with poor socio-economic status, symptoms of depression and competing demands for food and illicit drugs. Our findings support the need for targeted social, mental health and nutritional support strategies for IDU, including addiction treatment programs that may reduce the adverse effect of ongoing drug use on hunger, and visa versa. Further studies should seek to identify behavioral and biological pathways leading to food insufficiency in this population, and evaluate the effectiveness of support services in mitigating this adverse outcome.

\section{Statement of Authors' contributions}

All authors read and approved the final manuscript. AA, TK and SW designed research (project conception, development of overall research plant, and study oversight); JQ performed statistical analysis; AA, TK and SW wrote and made major contributions to the manuscript; JM and EW provided essential critical feedback on the manuscript; and TK had primary responsibility for final content.

\section{Acknowledgements}

We would like to thank VIDUS participants for their contribution to this study. We also thank Brandon Marshall and M-J Milloy for their administrative support. We would particularly like to thank the VIDUS participants for their willingness to be included in the study, as well as current and past VIDUS investigators and staff. We would specifically like to thank Deborah Graham, Tricia Collingham, Caitlin Johnston, Steve Kain, and Calvin Lai for their research and administrative assistance. The study was supported by the US National Institutes of Health (R01 DA011591) and the Canadian Institutes of Health Research (RAA-79918). Aranka Anema is supported by the Canadian Institutes of Health Research. Thomas Kerr is supported by the Michael Smith Foundation for Health Research and the Canadian Institutes of Health Research.

\section{Author details}

${ }^{1}$ British Columbia Centre for Excellence in HIV/AIDS, St. Paul's Hospital, Vancouver, BC, Canada. ${ }^{2}$ Department of Medicine, Faculty of Medicine, University of British Columbia, Vancouver, BC, Canada. ${ }^{3}$ Center for AIDS Prevention Studies, University of California San Francisco (UCSF), San Francisco, CA, USA. ${ }^{4}$ Positive Health Program, San Francisco General Hospital, University of California San Francisco (UCSF), San Francisco, CA, USA.

\section{Competing interests}

The authors declare that they have no competing interests.
Received: 27 May 2010 Accepted: 26 August 2010

Published: 26 August 2010

\section{References}

1. United Nations Office on Drugs and Crime (UNODC): World Drug Report 2010 [http://www.unodc.org/unodc/en/data-and-analysis/WDR-2010.html].

2. International Harm Reduction Association (IHRA): The Global State of Harm Reduction 2010: Key issues for broadening the response. [http://www. ihra.net/contents/245].

3. Wood E, Kerr T, Tyndall MW, Montaner JS: A review of barriers and facilitators of HIV treatment among injection drug users. AIDS 2008 22(11):1247-1256.

4. Nazrul Islam SK, Jahangir Hossain K, Ahmed A, Ahsan M: Nutritional status of drug addicts undergoing detoxification: prevalence of malnutrition and influence of illicit drugs and lifestyle. Br J Nutr 2002, 88(5):507-513.

5. Santolaria-Fernández FJ, Gómez-Sirvent JL, González-Reimers CE, BatistaLópez JN, Jorge-Hernández JA, Rodríguez-Moreno F, Martínez-Riera A, Hernández-García MT: Nutritional assessment of drug addicts. Drug Alcohol Depend 1995, 38(1):11-18.

6. Huggins ND, Khaled MA, Cornwell PE, Alvarez JO: Nutritional status and immune function in cocaine and heroin abusers and in methadone treated subjects. Res Commun Subst Abuse 1991, 12(4):209-215.

7. Riley ED, Vlahov D, Huettner S, Beilenson P, Bonds M, Chaisson RE: Characteristics of injection drug users who utilize tuberculosis services at sites of the Baltimore city needle exchange program. J Urban Health 2002, 79(1):113-127.

8. Baum MK: Role of micronutrients in HIV-infected intravenous drug users. J Acquir Immune Defic Syndr 2000, 25(Suppl 1):S49-52.

9. Quach LA, Wanke CA, Schmid CH, Gorbach SL, Mwamburi DM, Mayer KH, Spiegelman D, Tang AM: Drug use and other risk factors related to lower body mass index among HIV-infected individuals. Drug Alcohol Depend 2008, 95(1-2):30-36.

10. Normén L, Chan K, Braitstein P, Anema A, Bondy G, Montaner JS, Hogg RS: Food insecurity and hunger are prevalent among HIV-positive individuals in British Columbia, Canada. J Nutr 2005, 135(4):820-825.

11. Shannon K, Kerr T, Anema A, Weiser SD, Montaner JS, Wood E: Hunger and food insufficiency are independently correlated with unprotected sex among HIV+ injection drug users both on and not on HAART. 5th International AIDS Society (IAS) Conference on HIV Pathogenesis, Treatment and Care [Abstract No: 3310], Cape Town 2009

12. Wood E, Tyndall MW, Spittal PM, Li K, Kerr T, Hogg RS, Montaner JS, O'Shaughnessy MV, Schechter MT: Unsafe injection practices in a cohort of injection drug users in Vancouver: could safer injecting rooms help? CMAJ 2001, 165(4):405-410.

13. Wood E, Spittal P, Li K, Kerr T, Miller CL, Hogg RS, Montaner JS, Schechter MT: Inability to access addiction treatment and risk of HIV infection among injection drug users. J Acquir Immune Defic Syndr 2004, 36(2):750-754.

14. Radimer $\mathrm{KL}$, Olson CM, Campbell CC: Development of indicators to assess hunger. J Nutr 1990, 120(Suppl 11):1544-1548.

15. Kendall A, Olson CM, Frongillo EA Jr: Validation of the Radmier/Cornell measures of hunger and food insecurity. J Nutr 1995, 125(11):2793-2801.

16. Corneil TA, Kuyper LM, Shoveller J, Hogg RS, Li K, Spittal PM, Schechter MT, Wood E: Unstable housing, associated risk behaviour, and increased risk for HIV infection among injection drug users. Health Place 2006 12(1):79-85.

17. United Nations Population Fund (UNFPA): State of the World Population Report: Unleashing the Potential of Urban Growth - Vancouver: Prosperity and poverty make for uneasy bedfellows in world's most 'liveable' city. 2007 [http://www.unfpa.org/swp/2007/presskit/docs/ vancouver_feature_eng.doc].

18. Wood E, Hogg RS, Lima VD, Kerr T, Yip B, Marshall BD, Montaner JS: Highly active antiretroviral therapy and survival in HIV-infected injection drug users. JAMA 2008, 300(5):550-554

19. Hosmer D Jr, Lemeshow S: Applied Logistic Regression. New York: John Wiley Publishing, 22000.

20. Statistics Canada, Office of Nutrition Policy and Promotion: Income-related Household Food Security in Canada. Canadian Community Health Survey, Cycle 2.2. 2004 [http://www.hc-sc.gc.ca/fn-an/surveill/nutrition/ commun/income_food_sec-sec_alim-eng.php]. 
21. Office of National Drug Control Policy (ONDCP): What America's users spend on illegal drugs 1988-2000. NCJ-192334. White House, Washington, DC. 2001 [http://www.ncjrs.gov/ondcppubs/publications/pdf/ american_users_spend_2002.pdf].

22. Himmelgreen DA, Pérez-Escamilla R, Segura-Millán S, Romero-Daza N, Tanasescu M, Singer M: A comparison of the nutritional status and food security of inner-city drug-using and non-drug using Latino women. Am J Phys Anthropol 1998, 107(3):351-261.

23. Campa A, Yang Z, Lai S, Xue L, Phillips JC, Sales S, Page JB, Baum MK: HIVRelated Wasting in HIV-Infected Drug Users in the Era of Highly Active Antiretroviral Therapy. Clin Infect Dis 2005, 41(8):1179-1185.

24. Gambera SE, Clarke JA: Comments on dietary intake of drug-dependent persons. J Am Diet. Assoc 1976, 68(2):155-157.

25. Romero-Daza N, Himmelgreen DA, Pérez-Escamilla R, Segura-Millán S, Singer M: Food habits of drug-using Puerto Rican women in inner-city Hartford. Medical Anthropology: Cross-Cultural Studies in Health and Illness 1999, 18(3):281-298.

26. Wood E, Spittal SP, Small W, Kerr T, Li K, Hogg RS, Tyndall MW, Montaner JS, Schechter MT: Displacement of Canada's largest public illicit drug market in response to a police crackdown. CMAJ 2004, 170(10):1551-1556.

27. Wood E, Hogg RS, Bonner S, Kerr T, Li K, Palepu A, Guillemi S, Schechter MT, Montaner JS: Staging for antiretroviral therapy among HIVinfected drug users. JAMA 2004, 292(10):1175-1177.

28. Heflin CM, Siefert K, Williams DR: Food insufficiency and women's mental health: findings from a 3-year panel of welfare recipients. Soc Sci Med 2005, 61(9):1971-1982.

29. Alaimo K, Olson CM, Frongillo EA: Family food insufficiency, but not low family income, is positively associated with dysthymia and suicide symptoms in adolescents. J Nutr 2002, 132(4):719-725.

30. Anema A, Druyts E, Weiser SD, Lima VD, Fernandes KA, Brandson EK, Montaner JS, Kerr T, Hogg RS: High prevalence of depression among food insecure individuals receiving highly active antiretroviral therapy in Canada. 5th International AIDS Society (IAS) Conference on HIV Pathogenesis, Treatment and Prevention [Abstract No: 2142]. Cape Town 2009.

31. Weiser SD, Bangsberg DR, Kegeles S, Ragland K, Kushel MB, Frongillo EA Food Insecurity Among Homeless and Marginally Housed Individuals Living with HIV/AIDS in San Francisco. AIDS Behav 2009, 13(5):841-848.

32. Vogenthaler NS, Hadley C, Rodriguez AE, Valverde EE, Del Rio C, Metsch LR: Depressive Symptoms and Food Insufficiency Among HIV-Infected Crack Users in Atlanta and Miami. AIDS Behav 2010.

33. Gorber SC, Tremblay M, Moher D, Gorber B: A comparison of direct vs. self-report measures for assessing height, weight and body mass index: a systematic review. Obesity Reviews 2007, 8(4):307-326.

34. Drapeau V, King N, Hetherington M, Doucet E, Blundell J, Tremblay A: Appetite sensations and satiety quotient: predictors of energy intake and weight loss. Appetite 2007, 48(2):159-66.

doi:10.1186/1747-597X-5-20

Cite this article as: Anema et al:: Hunger and associated harms among injection drug users in an urban Canadian setting. Substance Abuse Treatment, Prevention, and Policy 2010 5:20.

\section{Submit your next manuscript to BioMed Central and take full advantage of:}

- Convenient online submission

- Thorough peer review

- No space constraints or color figure charges

- Immediate publication on acceptance

- Inclusion in PubMed, CAS, Scopus and Google Scholar

- Research which is freely available for redistribution

Submit your manuscript at www.biomedcentral.com/submit 